\title{
ALTERNATIVES TO SPECIAL CLASS PLACEMENT FOR EDUCABLE MENTALLY RETARDED CHILDREN
}

\section{Robert H. Bruininks and John E. Rynders ${ }^{1}$}

ALTERNATIVES TO SPECIAL CLASSES FOR EDUCABLE MENTALLY RETARDED
Public schools first provided day school programs for educable mentally retarded (EMR) children in Providence, Rhode Island, in 1896. These initial attempts to provide special education services to retarded pupils assumed the form of special classes. Originally started as an effort to provide instruction for children who were typically excluded from the public schools, these special classes were felt to embody a more flexible approach to education than institutional placement, since they enabled slow learners to enjoy normal social intercourse with children in regular classroom programs. Considered controversial even in 1896, the opening of the first special class for retarded children was announced by a Providence columnist in a sarcastic article entitled "The Fool Class" (Kanner, 1964). None other than Binet and Simon, inventors of the first widely used general intelligence scale, stated that "to be a member of a special class can never be a mark of distinction, and such as do not merit it, must be spared the record (Binet \& Simon, 1905, p. 82). Even though early authorities recognized the limitations of such placements, special classes continued to develop as the primary means of providing special education assistance to retarded chlidren.

Stimulated largely by support from parents' groups and professional organizations, special education provisions for retarded pupils have expanded dramatically in the past seventy-five years, particularly in the past twenty years. By 1966, more than 540,000 children were enrolled in programs for the mentally retarded (Mackie, 1969). Statistics indicate that by 1963 approximately 90 percent of the retarded children in special education programs were receiving instruction in self-contained special classes (Mackie, 1969): While the number of retarded children served by other organizational arrangements has undoubtedly increased since 1963, the self-contained classroom has continued to be the predominant pattern in special education for serving EMR children.

In recent years, disenchantment with practices in special education has been evidenced in the activities of a wide spectrum of individuals and agencies. A number of authors, for example, have discussed the inappropriateness of special class placement for educating many children classified as mentally retarded (cf. Christophos \&

1. Robert H. Bruininks and John E. Rynders are Assistant Professors, College of Education, The University of Minnesota.

(C) Love Publishing Company, 1971 
Renz, 1969; Deno, 1970; Dunn, 1968; Johnson, 1962; Lilly, 1970). (Most of the present controversy has focused primarily on the issue of special class placement for borderline retarded children with IQ's between approximately 70 and 85 . The present authors believe that many of the arguments and issues in this area may be equally applicable to the problems of providing services to more seriously retarded children.) The growing disenchantment with prevailing practices in special education reflected in recent articles has resulted largely from the disappointing findings of empirical studies exploring the efficacy of special class placement for retarded children, and from the placement of disproportionate numbers of minority group children in special education classes (Chandler \& Plakos, 1969; Dunn, 1968; MacMillan, 1971; Wright, 1967).

An article by Dunn (1968) has been a catalyst for much controversy and introspection among special educators over the issue of special class placement for retarded children. The central thesis of Dunn's paper is that special educators have been guilty of imposing special class placement on mildly retarded children, particularly minority group children from low socio-economic status backgrounds. He further indicts special educators for their failure to develop viable administrative and curricular alternatives to special classes for mildly handicapped children. [The empirical support and logical rationale for the issues explicated by Dunn (1968) and others were thoroughly reviewed by MacMillan (1971) in a previous issue of Focus on Exceptional Children.]

Empirical findings, legal pressures, and social consciousness have created heated debate over the issue of how

FOCUS ON EXCEPTIONAL CHILDREN is published monthly except June, July, and August as a service to those concerned with mentally retarded and emotionally disturbed children. Subscriptions rates, $\$ 9.50$ per year. Copyright 1971 Love Publishing Company. All rights reserved. Reproduction in whole or part without written permission is prohibited. Printed in the United States of America. Second class postage is paid at Denver, Colorado.

$$
\begin{gathered}
\text { Executive and Editorial Offices } \\
6635 \text { East Villanova Place } \\
\text { Denver, Colorado } 80222 \\
\text { Telephone (303) } 757-2579
\end{gathered}
$$

\section{EDITORIAL BOARD}

Edward L. Meyen
University of Missouri
Richard J. Whelan
University of Kansas Medical Center
Georgia State University
Frances Missing
Senior Editor

the field of special education should respond to the needs of retarded children. Summarized in Table 1 are some of the more common arguments advanced for and against special class placement for EMR children. While the validity of certain arguments on both sides of the present controversy appears beyond dispute, our contention is that much of the present debate over special class placement for retarded children has tended to result in the development of extreme positions-either unqualified endorsement of present practices or strident calls for their total abolition.

It is time to discontinue the needless squandering of professional energy on the dialectics of the special class issue. Unqualified endorsement of arguments for radical change or complete obeisance to conventional patterns contributes little to resolving the current challenges of providing equal educational opportunity to all children.

Little improvement in services to children is likely to accrue from demands to replace one form of organizational inflexibility with another, equally rigid pattern. What is required is not simply that children in special classes be returned to regular classrooms with no further assistance, but rather that a wide array of flexible service arrangements, intervention strategies, and support systems be designed to serve both handicapped children and their teachers. A focus on alternatives might reduce the present conflict by bringing the forces of change and those of conservation into closer juxtaposition.

The primary purpose of this article is to outline and discuss possible alternatives to special classes for serving the educational and social needs of EMR children. Along with an explication of various administrative and curricular alternatives, descriptions of selected programs will be provided which present a broader range of curricular options for children and teachers than are presently available through special class arrangements. However, to provide context for a discussion of administrative alternatives to special class placement, the following section presents a brief discussion of research findings and selected assumptions bearing on the controversy over special class placement for retarded children.

\section{GENERAL FINDINGS AND ASSUMPTIONS}

George Santayana once wrote that "those who do not remember the past are condemned to relive it." Special educators might in the future avoid many of the difficulties that have beset the development of past programs by examining the history of research and implementation of special classes for EMR children. Presented below are brief discussions of research findings and persistent assumptions related to this controversy. 
Table 1

Selected Positions on Special Class Placement for

EMR Children ${ }^{\mathrm{a}}$

Pros

Cons

1. Research evidence indicates that mentally retarded children in regular classrooms are usually rejected by more able classroom peers.

2. Mentally retarded children in regular classrooms experience loss of self-esteem because of their inability to compete with more able classroom peers.

3. It is logically absurd to assign children to instruction without considering differences in ability or achievement levels.

4. Evidence on the efficacy of special classes is inconclusive since most studies possess significant flaws in research design.

5. Criticisms of special classes are based ostensibly upon examples of poorly implemented programs.

6. The alternatives to present practices are less desirable and would lead to a return to social promotion as an approach to dealing with mildly retarded children.

7. Properly implemented special classes are optimally suited to deal with the major learning problems of retarded children.

8. Special class arrangements should not be unfairly indicted for mistakes in diagnosis and placement.

9. A democratic philosophy of education does not dictate that all children have the same educational experiences, but that all children receive an equal opportunity to learn according to their individual needs and abilities.
1. Special class placement isolates retarded child from normal classroom peers.

2. Special class placement results in stigmatizing the retarded child, resulting in a loss of self-esteem and lowered acceptance by other children.

3. There is little evidence to support the practice of ability grouping for retarded or normal children.

4. Mildly retarded children make as much or more academic progress in regular classrooms as they do in special classrooms.

5. There is little point in investing further energy in improving special classes, since this arrangement poorly serves the social and educational needs of children.

6. Other more flexible administrative and curricular arrangements should be developed to supplement or supplant special classes.

7. Special class arrangements inappropriately place the responsibility for academic failure on children rather than upon schools and teachers.

8. The very existence of special classes encourages the misplacement of many children, particularly children from minority groups.

9. Special class placement is inconsistent with the tenets of a democratic philosophy of education because it isolates retarded from normal children, and vice versa.

${ }^{a}$ Most of the positions summarized in this table are based on recent articles by Dunn (1968), Milazzo (1970), Kidd (1970), Johnson (1962), Lilly (1970), and Christophos and Renz (1969).

The Evidence

During the past forty years over twenty studies employing a variety of research designs, instruments, and samples have reported findings concerning the efficacy of special class placement for EMR children. [The reader is directed to writings of Cegelka \& Tyler (1970), Goldstein (1967), Guskin \& Spicker (1968), Johnson (1962), Kirk (1964), and MacMillan (1971) for thorough discussions of the research findings in this area.] Early efforts focused on contrasting retarded children enrolled in regular classes with those in special classes within the same school systems. These studies typically found special class enrollees inferior to their regular class counterparts in academic areas, but comparable or slightly superior on measures of classroom adjustment and personality (Cegelka \& Tyler, 1970; Kirk, 1964).

Since children are typically referred for special class placement for severe behavior problems as well as learning difficulties, retarded children in regular classes probably enjoyed advantages in achievement and may have possessed higher motivation to succeed in school-relevant tasks. This obvious selection bias favoring regular class 
children, along with the inadequate instrumentation employed to measure classroom adjustment and personality, rendered these early findings invalid.

Later studies sought to control sampling bias by using regular class comparison groups in school districts without special education classes (Blatt, 1958; Cassidy \& Stanton, 1959). The findings of these studies were equivocal, with one study reporting no significant differences between regular and special class groups in achievement (Blatt, 1958), while the other reported differences favoring the regular class sample (Cassidy \& Stanton, 1959). Again a sampling bias was present favoring the regular class retardates, since the regular class samples probably included a greater number of children who would not have been referred for placement in special classes (Goldstein, 1967).

Goldstein, Moss, and Jordan (1965) attempted to control for problems of selection bias by randomly assigning retarded children to regular or special class placements upon entrance to the first grade. Attempts were also made in this study to avoid the methodological shortcomings of previous studies by improving instrumentation, by standardizing the special class curricula, and by employing recently certified special class teachers. After four years there were no significant differences between the two groups in either IQ gains or academic achievement. Post hoc analyses of small numbers of low-IQ (below 81) and high-IQ (above 80 ) children revealed that the lowIQ children profited more academically from a special class placement, while the high-IQ children achieved more in the regular classroom setting.

Evidence from studies on the efficacy of special classes is largely inconclusive, and provides little information on the effects of such placements upon children. Moreover, findings on the effects of placement on the personality development and personal adjustment of the retarded are particularly contradictory, leading MacMillan (1971) to conclude:

\begin{abstract}
... We do not yet understand the effects of placement on personality. On the one hand we find evidence . . . indicating that the child suffers in a special class, while on the other the evidence indicates that he suffers in a regular class. .... In other words . . . the child can't win-but all of the evidence is of questionable validity in terms of sampling bias, lack of control of preplacement experiences, and the questionable nature of the criterion measures (p. 1 ).
\end{abstract}

Inadequacies in research designs and problems of interpreting the findings of studies concerned with ascertaining the efficacy of special classes for EMR children lead inevitably to the conclusion that available evidence is less than conclusive, it is basically uninterpretable. As Nelson and Schmidt (1971) have noted, "Statements about the efficacy of special classes presuppose a number of prior statements such as efficacy for whom, efficacy under what circumstances, efficacy at what times, and efficacy for what goal ...." (p. 382-383). Until issues cited by Nelson and Schmidt are considered in efficacy studies of special classes, generalization of available data beyond sample populations is extremely hazardous. Equally evident is that knowledge about the efficacy of special classes contributes little toward resolving the present controversy. Available data can be applied with equal validity to arguments favoring the maintenance of special classes as well as to those recommending the abolition of such placements. The polemical arguments, in short, remain more political than educational (Engel, 1969), and gather little or no support from the nearly forty years of reported research.

One need that becomes painfully evident from a review of past research efforts is that researchers have chosen to ignore the possibility that existing administrative arrangements in special education may affect individual children in different ways. Furthermore, the validity of extant findings is based on a number of unproven assumptions regarding the nature of special class programs. The following section explores a few of the persistent assumptions which have guided the expansion of services for retarded children.

\section{Persistent Assumptions}

Throughout the past sixty years several persistent assumptions regarding the nature and purposes of special classes have been invoked to defend program expansion. It will be instructive to examine these assumptions in order to extend our perspective on the present controversy, as well as to improve our understanding of the issues involved in the development of programs for handicapped children.

Homogeneous grouping. Special class programs for retarded children were considered for instructional purposes as a means of narrowing the range of intragroup differences in children. The supposition was that children with IQ scores between 50 and 80 who were placed in special classes possessed highly similar instructional needs.

The contention that the range of IQ scores is reduced in special classes cannot be disputed. The range in special classes of individual differences on important educational characteristics, however, is not necessarily reduced correspondingly. In a large metropolitan area survey, the authors found that several special classes included children with reading achievement scores ranging from nonreading to sixth grade levels. The variability in other educationally relevant characteristics of these special 
classes was probably equally heterogeneous, resulting in groups of children with a wide rather than a narrow range of individual differences. Other studies have reported greater intragroup variability in performance on a variety of learning tasks among retardates than among normals (MacMillan, 1971). Thus, it appears that special classes do not necessarily contain children with highly similar learning needs and characteristics.

Concepts of diagnosis are in large part responsible for viewing children in special classes as homogeneous groups, defeating the intent to provide individualized instruction. Figure 1 depicts the tautological reasoning which underlies much of the diagnostic and testing efforts in special education. This Figure suggests that children are referred initially for specialized services because of specific problems in learning and/or adjustment. (No assumption is being made regarding the cause of the child's problem.) Following the initial referral, an assessment of the child is conducted in the areas of intelligence and achievement. If the child scores low enough on the intelligence test he is generally referred for special educa-

\section{Figure 1}

\section{Typical Diagnostic Sequence in Special Education}

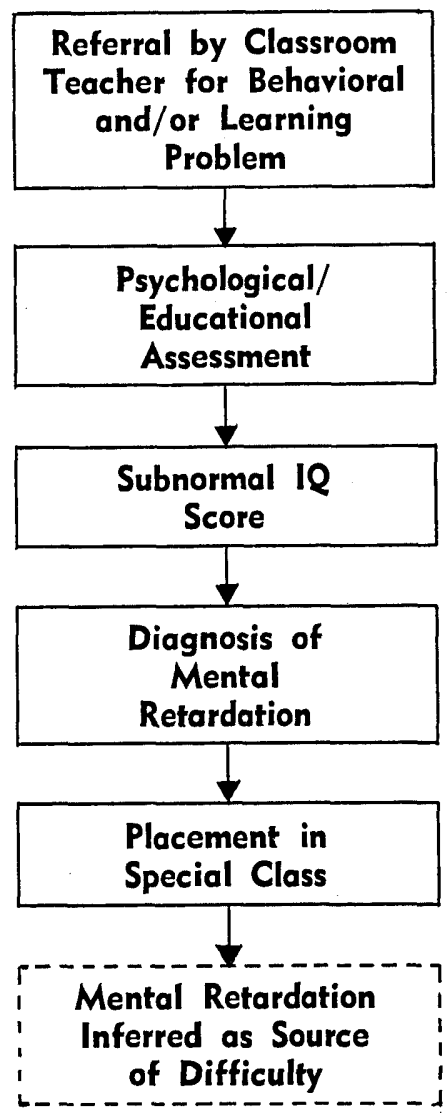

tion assistance. By the end of the diagnostic sequence, however, mental retardation emerges as a causal explanation of the child's problem(s). This specious ascription of causation to correlated events often leads to the conclusion that the problems of children with similar IQ scores arise from the same source (Reynolds, 1970). Once an assignment is made to a special class there is a strong inclination to view children on the basis of group rather than individual criteria.

No available evidence supports the contention that special classes include children exhibiting similar educational needs, or that such placements lead to greater individualization of instruction. Unfortunately the assumption that children with similar intelligence quotients also resemble each other closely on other behavioral characteristics was seldom questioned in the development and implementation of programs.

Unique curriculum. Another persistent assumption in special education was that special classes afforded an opportunity to provide specialized curriculum for retarded children. While special educators publicly castigated the concept of the "watered-down" curriculum, programs in special classes actually closely resemble the types of experiences provided children in regular classes. In reviewing over 250 curriculum guides for mentally retarded children, Simches and Bohn (1963) were led to conclude:

\section{... The indication is that special educators feel, that although much work is yet to be done in regard to refinement, what exists are essentially different curricula. . . . What does exist is the rephrasing and reemphasizing of available courses of study used for normal children that do not even have the benefit of the form, structure, and sequence connected with standard curriculum development (pp. 86, 115).}

The conclusions of Simches and Bohn suggest that the assumption of differentiated, carefully sequenced curricula for mentally retarded pupils was rarely implemented in special class programs.

Specially trained teachers. With the development of special classes, certification standards for teachers were prescribed in most states. State, college, and university training standards for special class teachers typically specified lists of courses for certification rather than competencies necessary to teach children. The only truly comprehensive survey concerned with determining the competencies necessary to teach retarded children was published by Mackie, Williams, and Dunn (1957). For some unknown reason, however, the issue of what competencies special class teachers should possess was given only token consideration in professional literature or training programs in special education.

There is little evidence that training programs in special 
education have systematically evaluated the extent to which their trainees have mastered prescribed and agreed upon teaching skills. Instead, the stress in training programs has ostensibly been placed upon increasing the number of available teachers rather than on the quality of training, which leads to what Davis (1970) has characterized as a condition of "demand-degradable teacher standards" in special education. The assumption that specially trained teachers are necessary to teach retarded children in special classes remains untested. Moreover, there is little evidence that special educators have established unique training programs for teachers, or that they have evaluated the extent to which certified special education teachers possess the skills considered necessary to teach retarded children. While general educators may also stand indicted on these issues, the presumed advantages of specially trained teachers educating retarded children as yet remains unproven.

Summary. The persistent assumptions that special classes provided an optimal setting for individualized instruction, for providing differentiated curricula for retarded children, and for employing specially trained teachers remain untested. Ambiguity in goals and practices has resulted in a general failure to effectively implement special class programs (Brown, 1968; MacMillan, 1971). Considerable doubt exists, moreover, that special classes even if properly implemented are optimally suited to provide EMR children with individualized instruction, specialized curricula, or specially trained teachers.

The historical development of special classes provides instructive lessons to guide the future development of services for retarded children. The first lesson is that the tendency to grasp at convenient nostrums as complete solutions for complex educational problems should be resisted. The second and equally important lesson is that successful implementation of programs requires that the assumptions underlying program development be verifiable (Nelson \& Schmidt, 1971), and that programs be continually examined to assess whether assumptions are being appropriately implemented. A third lesson is that programs in special education have evolved without the benefit of clearly stated goals and sound philosophical concepts. Because assumptions underlying the development of special classes have not been monitored, service arrangements have closely paralleled the educational program in regular classes. In short, very little of special education for retarded children could be considered either special or specialized.

\section{EDUCATIONAL ALTERNATIVES}

Over the past seventy-five years special classes have emerged as the primary vehicle for providing educational opportunity for retarded children. Unfortunately, during this period we have learned little about the precise effects of special education services upon children. The search for effective models for serving EMR children has been hindered significantly by the implementation of programs which exemplify unclarified purposes and assumptions, as well as by the general failure of special educators to develop service models based upon accepted philosophical tenets.

The search for viable educational alternatives for EMR children might be facilitated by applying general philosophical principles to efforts in program development. The normalization principle is gaining increasing acceptance among professionals in the field of mental retardation. When applied to problems of program planning and implementation, this concept appears to embody a philosophical principle of considerable potential. Developed in Scandinavian countries, "the normalization principle means making available to the mentally retarded patterns and conditions of everyday life which are as close as possible to the norms and patterns of the mainstream of society (Nirje, 1969; p. 181)." Application of the normalization principle to special education programs implies that retarded children should experience the educational and social activities generally provided normal children. Applying this principle to the problems of planning educational services for retarded children would lead to changes in existing service arrangements as well as in practices of allocating children to special education programs. If adopted, the normalization principle would encourage the development of an array of service systems, all designed to maximize the meaningful integration of EMR children into normal school routines. Under this principle no child would be placed directly into segregated service arrangements unless it was certified that he was unable to be served in normal settings, even with specialized assistance.

Another concept which might help guide program development is that of individualization. Considered as raison d' être of special education, individualization more than any other word has served to symbolize special education. The concept is especially useful when defined as consisting of "planning and conducting, with each student, general programs of study and day-to-day lessons that are tailor-made to suit his learning needs and his characteristics as a learner" (Heathers, 1971, p. 1).

A commitment to the concepts of normalization and individualization might lead to overdue changes in the way children are assigned to special education services. Presently, children are allocated to special education 
services ostensibly on the basis of categories-i.e., mentally retarded, deaf, etc. (cf., Reynolds, 1970). While categorical designations such as mental retardation serve as indicators of educational problems, they provide little information of value for designing educational programs for children (Reynolds, 1970). Simply diagnosing children as mentally retarded accomplishes little. Instead, categorical approaches to planning instruction encourage practices of making qualitative rather than quantitative distinctions among children. Educational decisions about appropriate teaching strategies and organizational arrangements must be based upon relevant behavioral variables which predict differentially among contrasting instructional alternatives.

Stressing normalization and individualization in program development might clarify educational alternatives and identification procedures in assigning children to alternative, specialized programs. Perhaps a good way to gain some perspective on the matter of alternatives is to view the school as encompassing a variety of possible influences which contribute to each child's development. These influences take the form of (1) administrative arrangements, (2) instructional roles of staff, and (3) instructional materials. The impact of educational forces on the development of children, as depicted in Figure 2, can be conceptualized as representing thrusts of services in a school program.

Implicit in Figure 2 is the contention that the educational difficulties experienced by children result from the complex interaction of several factors, including the child's characteristics, instructional content and quality, and ad-

\section{Figure 2}

\section{Educational Influences on the Development of the Retarded Child}
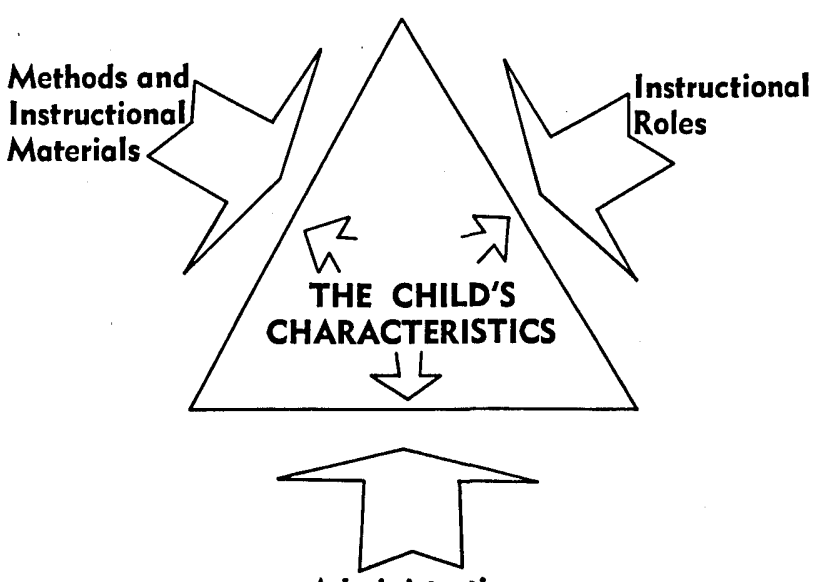

Administrative

Arrangements ministrative arrangements. [See Szasz (1970) and Clark (1970) for excellent discussions related to the causes of pupil failure.] If instructional alternatives shown in this Figure are viable, continuous, and sensitized to the needs of children, the retarded child is likely to thrive. On the other hand, if the options available are limited and insensitive to the individual needs of children, educational development of retarded children will most likely be impaired. The child's educational development is thus dependent on the personal-social-cognitive qualities he manifests in interaction with the personal-professional qualities of instructional staff with whom he comes into contact:

An expanded concept of educational alternatives to special classes emerges in Table 2. Implied is the need for increased sensitization to the needs of handicapped children through resources potentially available in both regular and special education programs. The material in this Table and in Figure 2 suggests that special education assistance need not be defined simply in terms of administrative arrangements, but may also be defined in terms of instructional roles and specialized curricula. The undue stress by special educators on the issue of administrative arrangements has tended to obscure the rich potential for achieving truly differentiated instruction for children through alterations in curricula and/or professional roles.

In this section, selected aspects of philosophy, instructional methods and materials, instructional roles, and administrative arrangements were presented as primary ingredients in developing and implementing special education programs for retarded children. In the following section several programs will be discussed which present interesting, contrasting alternatives to special classes.

\section{PROGRAM PROFILES}

Individually Prescribed Instruction (IPI). IPI is an instructional system which is based on specific objectives, interlinked with diagnostic tools and teaching materials (Scanlon, 1971). It stresses assessment of pupil abilities and the continuous monitoring of pupil progress. As the pupil enters a new instructional situation, the teacher diagnoses his abilities through a placement instrument and an achievement pretest representing the objectives within a learning unit. Based on this initial assessment and her knowledge of the child's learning characteristics, the teacher writes a learning prescription utilizing the set of objectives and complementary instructional materials produced for the program. The teacher's role in an IPI program becomes that of progress analyzer, tutor, and instructional manager, in contrast to the more conventional teaching role of dispenser of instruction. 
Table 2

Educational Services for EMR Children

Personnel Roles
Instructional Resources

1. Paraprofessionals-support and extend the capability of classroom teachers.

2. Case managers - assume child advocacy roles, coordination of services, etc.

3. Child development specialists -expand the capability of classroom teachers to accommodate a wider range of individual differences.

4. Instructional specialists-serve regular and special education teachers in consultative roles.

5. Resource learning specialistsserve children directly and consult with classroom teachers; specialize in particular developmental areas (language development, mathematics, etc.)

6. Diagnostic specialists - diagnose educational problems; prescribe appropriate materials.

7. Special education tutorial personnel-provide short-term assistance to children.

8. Special class teachers - serve very small groups of children with severe educational handicaps.
1. Programmed learning materials and other self-instructional programs.

2. Instructional technologies-

a. teaching machines

b. computer assisted instruction

c. closed circuit TV

d. listening centers

e. language laboratories

f. etc.

3. Instructional materials centers.

4. Diagnostic and prescriptive instruction centers.

5. Specialized curriculum materials and remedial education systems.
1. Nongraded, open school arrangements-self-directed learning, individually prescribed instruction, etc.

2. Regular class - special education support to classroom teacher.

3. Regular class - special education assistance to classroom teacher; short-term ancillary services to child (tutoring, diagnosis, etc.).

4. Regular class-intensive special education assistance to children and classroom teachers.

5. Special class-some academic and non-academic instruction in regular classes.

6. Special class-only nonacademic contact in regular classes.

7. Special class-little significant contact with children in regular classes.

8. Special day school for retarded pupils-no significant contact with children in regular school settings.

9. Homebound instruction-individual instruction for children who are unable to attend school.

10. Residential school-contact with pupils in nearby community programs.

11. Residential school-no significant amount of contact with pupils in community programs.
The child's role is also somewhat different in an IPI classroom than in the traditional setting. Though he is in a standard classroom, the child acts as his own instructional agent by working toward mastery of objectives that have been prescribed for him. As he finishes a piece of work to his satisfaction, he turns it in to a teacher aide who scores it and informs the teacher of the student's progress. The teacher then represcribes work for him which coincides with that performance. When appropriate, she administers unit tests to determine content mastery and curriculum-embedded tests which measure progress toward an objective.

Based on principles of reinforcement theory, IPI is an instructional system designed to facilitate classroom learning through careful specification of objectives, pacing of instruction, and reward for mastery. Since this system 
does not depend on the attainment of any prerequisite achievement level, it is not dependent upon homogeneous grouping for its implementation. In an IPI classroom, retarded children might work at their own pace with normal peers without revealing their inadequacies in school learning which are often amplified in group instructional settings.

Downriver Learning Disability Center. The Downriver Learning Disability Center is an example of another program which emphasizes pupil assessment as an approach to planning instruction (School District of the City of Wyandotte [Mich.], 1971). The Center, supported by a consortium of twelve school districts, is an outpatient facility for learning disabled children in which specially trained staff accept individual referrals. In contrast to the IPI Program, which includes a complete program of assessment, instructional programming, management, and evaluation, the Downriver Center staff perform the assessment function only, relying on the child's home teacher and school to follow through with his instruction.

The classroom teacher initiates a referral to the Center by sending a request to the local district's special services department. The school psychologist for the district administers some preliminary tests to determine the child's eligibility for learning disability services. From the total number of children within each district, the local district or the private school selects their quota to be sent to the Center. This selection is usually based both on the child's needs and the teacher's ability to profit from the Center experience.

On an appointed day the child and his classroom teacher come to the Center. The teacher arrives before the child in order to participate in some preliminary discussion of the case and to attend a general orientation session in which the diagnostic tests are explained. The teacher observes the child being tested and views a slidetape presentation of a demonstration of materials likely to be recommended for her child.

Toward the end of the afternoon, a Center staff member coordinates a case staffing conference including the classroom teacher, building principal, remedial reading teachers, speech correctionist, school district diagnostician and other persons involved with the child. During this conference, particular attention is paid to recommendations involving instructional suggestions. The Center instructs the teacher in the use of the materials which have been recommended and provides her with materials if they are unavailable within the district.

Ten weeks after the assessment, a Center staff member pays a follow-up visit to the teacher to discuss the child's progress and to help update the recommendations. Center personnel are also constantly available to the teacher for consultation.

The Downriver Learning Disability Center offers a promising approach to augmenting the regular class teacher's assessment skills and knowledge of instructional strategies, thereby reducing the necessity for special class services.

The next two programs illustrate alternatives which emphasize the structuring of teacher roles and use of instructional materials.

The Educational Modulation Center. This program is aimed at the improvement of a child's specific educational skills so that he can remain in the regular class (Adamson \& Van Etten, 1970; Van Etten, 1969). According to the authors of the program, selection of appropriate materials constitutes an important and complex problem. Therefore, the Center has developed a retrieval system which matches a child's learning characteristics with the attributes of instructional materials which have been analyzed for specific content. Here is how the system works using a hypothetical case: A child is evaluated and found to be functioning intellectually at a level comparable to a six-year-old child. The evaluation has also revealed that the student has a deficit in alphabet recognition, and that he has been observed to respond best to auditory material.

What steps are required to retrieve the needed material? First the diagnostician, utilizing the prescriptive materials retrieval system, selects the descriptor card for alphabet recognition, the child's specific content disability. The second card selected is the descriptor card appropriate for an intellectual level of a six-year-old. The third descriptor card selected is for taped material suitable for alphabet recognition purposes. When these descriptor cards are placed over a light box, an illumination process refers the user to materials matching all these descriptors. By changing or eliminating various descriptor cards, large amounts of material can be searched in a short span of time.

Though materials prescription is the major thrust of the project, consultants are also provided who work in classrooms to assess a child's abilities and explore educational approaches in cooperation with his teacher. Other services include consultative help for schools wishing to use prescriptive teaching techniques, and a research program to sharpen the use of instructional methods and materials.

The Educational Modulation Center represents an inroad toward solving one of the major problems that has plagued special educators for a long time, i.e., the matching of instructional materials to selected characteristics of children.

Harrison Resource Learning Center. This program is located in an inner-city school in Minneapolis, Minnesota. 
Co-sponsored by the Department of Special Education at the University of Minnesota and the Minneapolis Public Schools, the Center has two purposes: (1) to provide direct prescriptive instruction to intellectually subnormal children enrolled in regular classes, and (2) to train special education students from the University in the skills of prescriptive teaching.

The Harrison Resource Learning Center is one example of how a school can alter the roles of its teaching staff by installing an educational alternative which can become an integral part of the school's teaching program. The resource teacher assumes direct responsibility for some daily instruction of children in areas of greatest educational need, as well as for assisting the child's classroom teacher in designing appropriate educational experiences.

Perhaps a brief case history would be helpful in illustrating the resource teacher's role. Charles (IQ $=68$ ) has been in a special class for retarded children for almost a year. When the Resource Center opened, Charles was one of the first children recommended for placement back into a regular class with support from the resource teacher. At first, Charles spent most of the school day in the Resource Learning Center. The resource teacher began by emphasizing experiences designed to improve his selfconfidence, while gradually increasing the demands placed upon him for achievement in basic school subjects. Over a period of two months, the length of time that Charles spent in regular class was gradually increased except for those periods in the regular class schedule when the material was beyond his skill level. During this period he gained more than one grade level in reading and almost two grade levels in arithmetic. His teachers and mother also reported a marked improvement in his attitude toward school.

Charles presently spends forty-five minutes per day in the Resource Center, receiving help primarily in reading. His resource and regular class teachers hope to reduce this out-of-regular-class time even further by designing instructional content that will permit him to progress without requiring an inordinate amount of the regular class teacher's attention.

In the first year of the program, eight special class children were returned to regular classes and an additional twelve out of twenty-eight regular class children who were on the waiting list for placement in special classes also received help. None of these children have been re-recommended for special class placement in the two years of the Center's operation.

Summary. The programs described above were chosen for discussion because they offer interesting and contrasting alternatives to special class placement for EMR chil- dren. Widespread adoption of these programs would be ill-advised, however, since there is insufficient evidence to judge their efficacy at the present time. Nevertheless, it appears that these programs are attempting to employ the principle of normalization by providing alternatives minimizing the perceived differences between the instructional experiences of retarded and normal children; and these programs appear to embody the principle of individualization by customizing instructional roles, instructional materials, and administrative arrangements to suit the learner's perceived needs and characteristics.

\section{SUMMARY}

The central thesis of this article is that polemical arguments for and against special class placement for EMR children have achieved their intended purpose of making special educators sensitive to the inadequacies of current practices. Now is the time to begin the painstaking development, implementation, and evaluation of a range of viable alternatives. As an antidote to the present controversy that grips the field of special education, further recommended is that less emphasis be placed upon conceptualizing the educational difficulties of handicapped children in terms of categories (Reynolds, 1970), unless such classifications can be translated into effective educational treatments.

If the principles of normalization and individualization are to become realities in the education of EMR children, general education must also become more accommodative to individual differences in children. Fortunately, there are examples where this accommodation is occurring such as: the Differentiated Staffing Program of Temple City (Stoner, 1969) in which teachers assume differing roles because of their competencies in specific instructional areas and strengths in dealing with particular learning attributes of children; ungraded schools which promote children on the basis of achievement and not on the basis of chronological age; open classrooms where young children play a major role in determining their instructional experiences (Silberman, 1970).

Special educators must invest greater resources in efforts to enhance the capability of general education to better accommodate the educational and social needs of handicapped children. Perhaps this point can be sharpened by viewing special education as developmental capital (Deno, 1970). Deno (1970) has recommended that special education serve as a vehicle of setting the general education system in competition with itself, initiating an internal challenge that will generate and sustain creative tension. In her words: 
The special education system is in a unique position to serve as developmental capital . . . to upgrade the effectiveness of the total public education effort. It has the motivation and the justification to enter into cooperative competition with regular education, to act as advocate for those children who fall out or are squeezed out of the educational mainstream's sieve-like bottom half ( Ibid., p. 231).

Attempts to improve present services for handicapped children should be firmly rooted in sound philosophical tenets. All too often special education programs have developed without proper consideration for statements of purpose and tests of assumptions. Ambiguity of purpose and failure to test the validity of assumptions have led to the practice of judging program effectiveness by the simple, expedient metric of program expansion. Special education services must be judged by their effects on the development of children as well as by the extent to which these services approximate those afforded children in general education.

At this time hasty attempts to abolish special classes seem unwise and premature. Instead, special class programs for EMR children should be restructured to serve only those children who cannot remain in a regular classroom, even with specialized assistance.

One major caveat must be considered in developing programs: special educators should avoid impetuous implementation of alternatives to replace special classes. Sudden implementation of programs without the necessary safeguards of objective evaluation leads inevitably toward institutionalizing program models without validating their effectiveness. The rush in many areas to replace special classes with resource rooms seems as premature and unwise as persistent recommendations to abolish special classes. Before any special education program is implemented, a number of prior questions must be pondered: (1) What are the goals of the program? (2) Whom should the program serve? (3) What are the major constituents of the program? (4) What services(curricula) should be provided in the program? (5) Upon what assumptions is the program based? (6) What are the roles of special and regular education personnel in the program? (7) What criteria should be employed to judge the effectiveness of the program? (8) Under what conditions is the program effective?

Above all special educators must shed their preoccupation with the special class issue and develop comprehensive research and development programs designed to increase the quality, variety, and availability of services to handicapped children. Further attempts to provide instructional alternatives to special classes for EMR children will likely lead to trivial results unless such efforts are accompanied by careful planning and evaluation. The interests of children we serve require that future research contribute to the development of programs by yielding information on the efficacy of services for individual children, rather than by focusing on the effects of treatments upon groups of children differing in a variety of schoolrelevant behaviors. This approach to research and evaluation in special education assumes that no program is best for all children, but that program effectiveness varies depending upon the characteristics of children, settings, and personnel. An approach to research focusing on individual differences rather than group characteristics might lead to both accretions in knowledge and improvements in services to handicapped children.

Work on the above article was supported partially by a grant (\#OE-09-332189-4533032) from the Bureau of Education for the Handicapped, U.S. Office of Education.

\section{REFERENCES}

Adamson, G., and Van Etten, C. "Prescribing via Analysis and Retrieval of Instructional Materials in the Educational Modulation Center." Exceptional Children, 1970, 36(7), 531-533.

Binet, A., and Simon, T. "Upon the Necessity of Establishing a Scientific Diagnosis of Inferior States of Intelligence." $L$ ' Année Psychologique, 1905, 11, 163-191. Reprinted in J. J. Jenkins and D. G. Patterson (Eds.), Studies in Individual Differences. New York: Appleton-Century-Crofts, 1961. Pp. 81-90.

Blatt, B. "The Physical, Personality, and Academic Status of Children who are Mentally Retarded Attending Special Classes as Compared with Children who are Mentally Retarded Attending Regular Classes." American Journal of Mental Deficiency, 1958, 62, 801-818.

Brown, L. F. "The Special Class: Some Aspects for Special Educators to Ponder." Education and Training of the Mentally Retarded, 1968, 3, 11-16.

Cassidy, V. M., and Stanton, J. E. "An Investigation of Factors Involved in the Educational Placement of Mentally Retarded Children: A Study of Differences between Children in Special and Regular Classes in Ohio." Cooperative Research Project No. 043. Columbus, Ohio: Ohio State University, 1959.

Cegelka, W. J., and Tyler, J. L. "The Efficacy of Special Class Placement for the Mentally Retarded in Proper Perspective." Training School Bulletin, 1970, 65, 33-68.

Chandler, J. T., and Plakos, J. Spanish-speaking Pupils Classified as Educable Mentally Retarded. Sacramento: California State Department of Education, 1969.

Christophos, F., and Renz, P. "A Critical Examination of Special Education Programs." Journal of Special Education, 1969, 3(4), 371-380.

Clark, K. B. "Fifteen Years of Deliberate Speed." Saturday Review, 1970, 53(12), 59-70.

Davis, F. R. "Demand-degradable Teacher Standards: Expediency and Profession Thanatos." Mental Retardation, 1970, 8(1), 37-39.

Deno, E. "Special Education as Developmental Capital." Exceptional Children, 1970, 37 (3),229-237.

Dunn, L. M. "Special Education for the Mildly Retarded-Is Much of It Justified?" Exceptional Children, 1968, 35, 5-22.

Engel, M. "The Tin Drum Revisited." Journal of Special Education, 1969 3(4), 381-384.

Goldstein, H. "The Efficacy of Special Classes and Regular Classes in the Education of Educable Mentally Retarded Children." In J. Zubin \& G. A. Jervis (Eds.), Psychopathology of Mental 
Development. New York: Grune \& Stratton, 1967. Pp. 580602.

Goldstein, H.; Moss, J. W.; and Jordan, L. J. "The Efficacy of Special Class Training on the Development of Mentally Retarded Children." Cooperative Research Project No. 619. Washington, D. C.: U.S. Office of Education, 1965.

Guskin, S. L., and Spicker, H. H. "Educational Research in Mental Retardation." In N. R. Ellis (Ed.), International Review of Research in Mental Retardation, Vol. 3. New York: Academic Press, 1968.

Heathers, G. "A Definition of Individualized Instruction." Paper presented at Annual Meeting of American Educational Research Association, New York, 1971 .

Johnson, G. O. "Special Education for the Mentally Handicapped -A Paradox." Exceptional Children, 1962 (Oct.), 62-69.

Kanner, L. A History of the Care and Study of the Mentally Retarded. Springfield, Ill.: Charles C. Thomas, 1964.

Kidd, J. W. "Pro-the Efficacy of Special Class Placement for Educable Mental Retardates." Paper presented at the 48th Annual Convention of the Council for Exceptional Children, Chicago, April 1970.

Kirk, S. A. "Research in Education." In H. A. Stevens \& R. Heber (Eds.), Mental Retardation: A Review of Research. Chicago: University of Chicago Press, 1964. Pp. 57-99.

Lilly, M. S. "Special Education: A Teapot in a Tempest." Exceptional Children, 1970, 37(1), 43-49.

Mackie, R. P. Special Education in the United States: Statistics 1948-1966. New York: Teachers College Press, 1969.

Mackie, R. P., Williams, H. M., and Dunn, L. M. Teachers of Children Who Are Mentally Retarded. Washington, D. C.: U.S. Government Printing Office (O.E. Bulletin, 1957, No. 3).

MacMillan, D. L. "Special Education for the Mildly Retarded: Servant or Savant?" Focus on Exceptional Children, 1971, 2(9), 1-11.

Milazzo, T. C. "Special Class Placement or How to Destroy in the Name of Help." Paper presented at the 48th Annual Convention of the Council for Exceptional Children, Chicago, April 1970.

Nelson, C. C., and Schmidt, L. J. "The Question of the Efficacy of Special Classes." Exceptional Children, 1971, 37(5), 381384.

Nirje, B. "The Normalization Principle and Its Human Management Implications." In R. B. Kugel \& W. Wolfensberger (Eds.), Changing Patterns in Residential Services for the Mentally Retarded. Washington, D. C.: President's Committee on Mental Retardation, 1969. Pp. 179-188.

Reynolds, M. C. "Categories and Variables in Special Education." In Exceptional Children in Regular Classrooms. Minneapolis, Minn.: University of Minnesota, 1970. Pp. 30-38.

Scanlon, R. G. "Individually Prescribed Instruction: A System of Individualized Instruction." Unpublished paper. Philadelphia, Penn.: Research for Better Schools, Inc., 1971.

School District of the City of Wyandotte. "The Downriver Learning Disability Center." Application for continuation grant. Wyandotte, Michigan, 1971.

Silberman, C. E. Crisis in the Classroom. New York: Random House, 1970.

Simches, G., and Bohn, R. "Issues in Curriculum: Research and Responsibility." Mental Retardation, 1963, 1, 84-87.

Stoner, M. Temple City Story. Temple City, Calif.: Temple City Unified School District, 1969.

Szasz, T. S. The Manufacture of Madness. New York: Harper and Row, 1970.

Van Etten, G. "Modulations Systems Research: A Proposed Model." Unpublished working paper of the Educational Modulation Center. Olathe, Kansas, 1969.
Whitehead, A. N. Science and the Modern World. New York: Macmillan, 1925.

Wright, J. S. Hobson vs. Hansen: Opinion by Honorable J. Skelly Wright, Judge, United States Court of Appeals for the District of Columbia, Washington, D. C.: West Publishing, 1967.

\section{A RESOURCE ROOM APPROACH TO INSTRUCTION FOR THE EDUCABLE MENTALLY RETARDED}

\section{Mildred W. Barksdale and Anna Pearl Atkinson ${ }^{1}$}

Trends in regular education such as flexible scheduling, non-graded elementary classes, differentiated staffing, team teaching, individualized instruction, and innovative uses of media support the exploration of delivery systems other than self-contained special classes for educable mentally retarded pupils.

A review of many studies which dealt with the efficacy of self-contained classes [Bennett (1932), Ainsworth (1959), Blatt (1958), Elenbogen (1957), Thurstone (1959) and others], strongly suggests modifications in the organization of programs for the educable mentally retarded. The Goldstein, Jordan, and Moss study (1965) which showed superiority of special classes over regular grades for educable mentally retarded children, did not suggest that special classes were the ideal placement for educable mentally retarded children. Additional support for change is indicated in the reports of Dunn (1968), Johnson (1969), Barksdale (1970), and Lilly (1970), which dealt with effects of poverty and race upon classification as educable mentally retarded.

In 1967 the Atlanta, Georgia, school system was faced with a long waiting list of elementary school children who had been identified as educable mentally retarded. The system was unable to employ enough trained teachers or provide adequate classroom space for all of these children in its special education program. The administration approved a proposal for a resource room.

A pilot project was initiated in two elementary schools in September 1967. One of the schools was located in the inner city, the other was in a middle class neighborhood. Both schools had waiting lists of identified educable mentally retarded children; they were overcrowd-

1. Mildred W. Barksdale is Professor of Special Education, Georgia State University, Atlanta, Georgia. Anna Pearl Atkinson is Coordinator of Programs for the Mentally Retarded, Atlanta Public Schools, Atlanta, Georgia. 
ed, and they lacked space for self-contained special classes.

The objectives of the resource room plan were to:

1. Develop and implement an instructional program which would attack some of the learning problems of children identified as educable mentally retarded through concentrated sessions of individual and small group instruction.

2. Provide an organizational pattern whereby educable mentally retarded pupils could remain in a regular classroom and be scheduled to a resource room for clinical teaching.

3. Involve special education and regular classroom teachers, through cooperative planning, in the use of diagnostic tools, teaching methods and materials, and continuous assessment procedures.

4. Provide a model wherein one special education teacher could deal with the special learning problems of from 24 to 32 pupils.

5. Involve the school principal in the orientation process and throughout the program, in order to alleviate misunderstanding among the faculty and in the community.

6. Provide a continuous in-service program for the regular classroom teachers and other school personnel.

7. Determine if the value of a cooperative resource room approach could be demonstrated by the overall achievements of educable mentally retarded pupils.

\section{ORIENTATION}

The first phase of the project implementation was orientation. A three day in-service planning and training workshop was held prior to starting the project. The participants were the regular class and special education teachers from the two schools who would be involved in the project, the two principals, and two educational aides. The workshop included discussions and demonstrations pertaining to:

1. rationale for change

2. "selling" the new plan to the total school staff and the parents of the children to be involved

3. organization and administration of the resource room

4. scheduling of pupils

5. cooperative planning between regular classroom and special education teachers

6. diagnostic teaching methods
7. duties of educational aides

8. equipment and teaching materials

9. evaluating pupil progress

10. curriculum content

11. area resource staff responsibilities

\section{INSTRUCTIONAL MODEL}

The second phase was concerned with an instructional model and roles of team members. The pilot project was designed to permit the retarded child to remain with his chronological agemates, with the concomitant rewards of regular class participation, yet have the benefit of a specialized attack upon his learning problems. The plan would avoid the disruption of social groups and the possible stigma attached to special class placement. Hopefully, it would also result in the return of some children to the regular classroom on a full-time basis.

During the first year, the team in each school was composed of one special education teacher; regular classroom teachers from grades $3,4,5$, and 6 ; and one educational aide. Four groups of pupils were assigned according to chronological age.

The second year, 1968-69, the students moved up one grade level and a seventh grade teacher joined the team in each school. Because of chronological age, six students entered the high school special education program. There were 26 children scheduled in each resource room with one special education teacher and one aide.

In the third year, 1969-1970, the team in each school was composed of four regular class teachers, one special education teacher and three aides. The special education teachers worked with 34 pupils, including 22 who were in the original pilot group. One aide worked with the special education teacher full time. The other two aides were scheduled in the regular classes where they worked almost exclusively with children who were assigned to the resource room and children needing the same kind of reinforcement activities or supportive assistance.

The special education teachers were experienced and certified in teaching the educable mentally retarded. They spent an average of one hour and fifteen minutes working with each group. Their duties included:

1. Scheduling groups to the resource room.

2. Diagnosis of pupils, writing lesson plans, and instructing pupils.

3. Working with regular classroom members of the team in the selection of units or work, instructional materials, and evaluation of pupils.

4. Periodic observation of pupils in the regular classroom. 
5. Consulting with parents.

6. Serving as resource teacher to other teachers in the school and working with psychologists.

The suggested schedule for the special education teachers was:
8:30-9:00 Planning and preparation
9:00-10:15 Instructional Session, Group I, 6-10 per group
10:15-11:30 Instructional Session, Group II
11:30-12:00 Lunch
12:00-1:15 Instructional Session, Group III
1:15-2:30 Instructional Session, Group IV
2:30-3:15 Conference time with students, parents, regular teachers, other professional per- sonnel.

The special education teacher in each school was able to make brief visits to the regular grades from which her pupils came during any of the instructional periods, due to the presence of a full-time supportive person in the resource room.

The resource rooms were furnished and arranged for small groups and individual activity. Each room was equipped with a tape recorder, controlled reader, language master, filmstrip projector, record player, and a listening station with eight earphones. A variety of instructional materials was available, including many of the well-known programmed learning series as well as materials which could be used creatively by the teacher, aide, and pupils.

\section{INSTRUCTIONAL PROGRAM}

The overall objective of the instructional program in the resource room was to make a systematic attack upon the child's specific learning problems. The special education teacher assessed each pupil's readiness for learning and his level of achievement through the use of a variety of formal and informal diagnostic procedures. The special teacher and the regular class teacher identified behavioral objectives, selected appropriate learning experiences, and planned lessons and units of work to meet the needs of individual pupils. Instruction was given individually or in small groups of three to four pupils. Depending upon the nature of the lessons, the pupils worked with the teacher, under the guidance of the aide, and independently during some portion of the period.

The younger and less mature children who were scheduled to the resource room were provided with an intensive program of sensory training, concept formation, language development, and reading and number experiences. Follow-up of the individual prescriptions was car- ried out by the regular classroom teachers in small and large groups with peers sometimes serving as tutors. Regular class time was scheduled for phonetic training, story telling, listening, role playing, and academic readiness activities. Carefully selected instructional units were also used by the regular class teachers.

The resource room experiences of the older and more mature children centered around perceptual organization, concept and language development, skills development in the basic school subjects, and counseling. The regular class teachers often used the unit approach to reenforce prescriptions and to extend knowledge of the world of work. The educational television program Count Down For the 70s and other materials prepared by the Special Occupational Information Project of Atlanta Schools provided high interest, multi-sensory activities for classroom use.

Throughout the program the teachers used various means to measure the degree to which learning had taken place, thereby evaluating the progress of the pupils as well as judging the effectiveness of their plans and presentations. Where progress was evident, the teacher moved on to other instructional levels. When the evidence showed that satisfactory learning had not taken place, the teacher modified procedures, initiated reviews, or took other steps to help bring about the desired change in the pupil's behavior. Of course, continued lack of achievement indicated a need for reassessment of the pupil's readiness for the particular learning experience, rewriting of program, and recycling the revised lessons. By following this system of assess-instruct-measure progress, the teacher gradually built an individualized program which was sequential and organized in terms of the pupil and his specific learning deficits.

\section{EVALUATION}

The effectiveness of the resource room plan for attacking the learning problems of children identified as educable mentally retarded was shown by this pilot program. School personnel have indicated that the model has had the twofold effect of providing pupils membership in the social world of the regular class and instruction which accelerated academic success. Formal and informal observations have been used to collect a body of meaningful data which support this conclusion.

There were 64 identified EMR children included in the pilot program; 32 in School A and 32 in School B. The subjects were 52 boys and 12 girls, age range 7 through 13. All had been administered the Stanford Binet Form LM by a school psychologist; the IQ range was 50 to 76 . The Wide Range Achievement Test was also administered 
to each child at the time of the psychological evaluation. The Mean Reading Grade was 1.2; the Spelling grade was 1.3; and the Arithmetic grade was 1.5. This test information, in addition to other objective measures recorded in the cumulative records of the school, was incorporated into the child's test profile.

The resource room teacher administered the Metropolitan Achievement Battery, Form A, as a pre-test instrument in September 1967. The range of test scores in Word Knowledge was 3.1 to 1.0 ; Word Discrimination 3.3 to 1.1; Reading 3.2 to pre-readiness. The range of scores in Arithmetic Computation was 3.7 to 1.0 and Problem Solving 2.0 to 1.1. The Mean scores in both schools were:

$\begin{array}{lcc} & \text { School A } & \text { School B } \\ \text { Word Knowledge } & 1.3 & 1.7 \\ \text { Word Discrimination } & 1.2 & 1.5 \\ \text { Reading } & 1.1 & 1.3 \\ \text { Arithmetic: } & & \\ \quad \text { Computation } & 2.0 & 2.3 \\ \quad \text { Problem Solving } & 1.0 & 1.4\end{array}$

The post-test results from the Metropolitan Achievement Battery B administered in May 1970 indicated significant academic improvement. The range of test scores in Word Knowledge was 5.2 to 1.5; Word Discrimination 5.8 to 1.4; and Reading 5.8 to 2.2. The Mean scores were:

$\begin{array}{lcc} & \text { School A } & \text { School B } \\ \text { Word Knowledge } & 3.1 & 3.4 \\ \text { Word Discrimination } & 2.6 & 3.0 \\ \text { Reading } & 3.0 & 3.5 \\ \text { Arithmetic: } & & \\ \quad \text { Computation } & 2.4 & 2.5 \\ \quad \text { Problem Solving } & 2.0 & 3.4\end{array}$

Subjective evaluations included teacher observations and informal observational questionnaires developed by the resource room teachers for regular class teachers, administrators, pupils, and parents.

Each year, pupils were reevaluated with individual psychological examinations that were administered by the school psychologists. By the end of the third school term, ten of the original sixty-four pupils identified as educable mentally retarded had been returned to the regular classroom, and follow-up indicated they were progressing in the regular class without resource room teacher services or support. Principals and teachers reported that there were noticeable changes in the pupils attitudes toward themselves, their teachers and peers, and the school in general. Parents of the children involved were especially enthusiastic in their appraisals of the plan. In general, evaluations indicated that the processes of assessment, individualized programming, and reteaching which assured degrees of success, were desirable for children who might have otherwise been placed in self-contained classes for the educable mentally retarded.

\section{CONCLUSIONS}

There seems to be justification for continuation of the resource room as one delivery system for children identified as educable mentally retarded. The model is particularly recommended for inner city schools where social and economic deprivations account for such a high percentage of children who have low scores on standardized intelligence tests. The improvement in attitudes toward self, parental enthusiasm, lack of stigma attached to labeling, in-service training for regular class teachers, and the wise use of supportive personnel all support this model as an alternate means of providing special education for a large number of children who would otherwise be left without special help.

\section{REFERENCES}

Ainsworth, S. H. "An Exploratory Study of Educational, Social and Emotional Factors in the Education of Mentally Retarded Children in Georgia Public Schools." (U.S. Office of Education Cooperative Research Program, Project No. 171 (6470).) Athens, Georgia: University of Georgia, 1959.

Atkinson, Anna Pearl. "An Integrated Approach to Instruction for the Educable Mentally Retarded." Unpublished Sixth-year Research Project. Atlanta University, Atlanta, Georgia, 1967.

Barksdale, Mildred W. "Mentally Retarded and Culturally Deprived Children: Some Parallels. Phylon-The Atlanta University Review of Race and Culture 31: 48-53, 1970.

Bennett, A. A Comparative Study of Subnormal Children in the Elementary Grades. New York: Teachers College, Columbia University, Bureau of Publications, 1932.

Blatt, Burton. "The Physical, Personality, and Academic Status of Children Who Are Mentally Retarded Attending Special Classes as Compared with Children Who Are Mentally Retarded Attending Regular Classes." American Journal of Mental Deficiency, 62: 810-18, 1958.

Dunn, L. M. "Special Education for the Mildly Retarded-Is Much of It Justifiable? Exceptional Children, 35: 5-22, 1968.

Elenbogen, M. L. "A Comparative Study of Some Aspects of Academic and Social Adjustment of Two Groups of Mentally Retarded Children in Special Classes and in Regular Grades." Dissertation Abstracts, 17: 2497, 1957.

Goldstein, H., Jordan, L., and Moss, J. W. "The Efficacy of Special Class Training in the Development of Mentally Retarded Children." Project No. 162. Washington: U.S. Office of Education, 1965.

Johnson, John L. "Special Education in the Inner City: A Challenge for the Future or Another Means for Cooling the Mark Out?" Journal of Special Education, 3: No. 3, 241-251, 1969.

Lilly, M. S. "Special Education: a Teapot in a Tempest." Exceptional Children, 37: 43-48, September, 1970.

Thurstone, Thelma G. "An Evaluation of Educating Mentally Handicapped Children in Special Classes and in Regular Grades." (U.S. Office of Education Cooperative Research Program," Project No. OE SAE-6452.) Chapel Hill: University of North Carolina, 1959. 


\section{CLASSROOM FORUI}

Edited by Austin J. Connolly, University of Missouri

\section{PROBLEM 10}

There are three classes for the educable mentally retarded in our elementary school. Because the special class curriculum varies from the regular program, our principal has requested that we develop our oun report card. Do you have any suggestions?

Your initial objective should be to identify the specific purpose or purposes you wish the report card to serve. While it is acknowledged that the report card is an attempt to convey a child's scholastic performance, is this in comparison to other children his age? with his special class peers? or to his own potential? What are the criteria upon which it would be useful to have measures recorded?

Having identified your needs and purposes, you are now ready to determine the areas in which the regular report card would be inadequate. It is unlikely that any report card will completely meet your needs. Consequently, you should consider integrating such things as parentteacher conferences and narrative reports. Generally, parent conferences are held at the conclusion of the first grading period. Such a conference should be structured to maximize the two-way transmission of information. Such a conference permits the teacher to review with the parents her philosophy on grading, the report card, and aspects of the child's performance. This conference can also build the foundation and confidence for future narrative and objective reports.

In developing a report card, adequate space should be provided for narrative comments. Narration provides the teacher with the opportunity to personalize the evaluation, reinforce subtle improvements, and identify trends, concerns, etc. While many reports contain a space for general comments, this lacks the necessary specificity and is often not used. It is better to delineate some space for comments particularly in the area of personal development and adjustment. Thus, comments might be addressed specifically to social development and adjustment, work and study habits, and physical development and adjust- ment. The provision of space in the report card does not negate the need for objective indices in the aforementioned areas nor in subject matter areas.

Regarding objective indices, you might consider using behavioral objectives. Such objectives need not be comprehensively written, but do need to identify a particular skill or aspect of knowledge which is a desired outcome of the instructional program at a prescribed level.

Such a scale is relatively easy to develop and has great merit. The first step in constructing a scale is to decide on topic areas, i.e., reading, oral communication, writing and spelling, arithmetic, health and safety, citizenship, vocational development, etc. The second step is for the teacher or teachers at each level to identify 5-10 objectives they wish the children to achieve in each topic area, i.e., primary arithmetic-rational counting from one to ten. At the conclusion of a grading period a child is evaluated according to whether he has attained the objective, is making significant progress towards the objective, has failed to make progress toward the objective, or has not had an opportunity to attempt the objective.

A report card comprised of objectives informs parents not only of the child's performance but also of the teacher's instructional goals. Sharing of such information is essential if education is to extend beyond the parameters of the six hour day.

\section{PROBLEM 12}

I have been a teacher for two years but continue to have problems motivating my students. Are there some particular techniques or procedures that you could recommend for motivating special education students?

All readers are invited to send their solution to Problem 12. The November 1971 issue will summarize contributions by readers. Complimentary subscriptions will be awarded each month for the best solutions. Send your response to the Editorial Offices, Focus on Exceptional Chlidren, 6635 East Villanova Place, Denver, Colorado 80222.

FOCUS ON EXCEPTIONAL CHILDREN back issues are available. Single copies $80 \%, 2-9$ copies $70 \phi$, and 10 or more copies $50 \phi$ each. 